\title{
De Lisboa para Sul Um Território Sustentável?
}

Vítor Matias Ferreira*

$\mathrm{R}$ o texto pretende equacionar algumas das condições de sustentabilidade desse território, tendo como referência empírica duas pesquisas de natureza e com objectivos bem distintos entre si. Para um tal debate, apresenta-se um quadro analítico estruturado em torno das noções de Território, Património e Cultura. No final, são apresentadas, de modo um tanto esquemático, diversas questões dilemáticas que enunciam alguns dos temas de uma necessária problematização do desenvolvimento sustentável do Sul do país.

Palavras-chave: Desenvolvimento sustentável; Território, património e cultura; Dilemas da sustentabilidade; Lisboa e o Sudoeste.

\section{Contexto}

O desafio do texto que se segue ${ }^{1}$ é o de procurar ilustrar uma especificidade paradigmática do Sul do continente português, partindo de duas pesquisas temporalmente demarcadas, de natureza técnico-científica distinta e com objectivos diferenciados entre si. Desses estudos, no primeiro caso Lisboa está no centro da atenção, enquanto que, na outra investigação, é o Sudoeste do continente que constituiu o objecto das pesquisas. Tratando-se de duas investigações com objectivos diferentes, como se disse, o respectivo enfoque analítico também se diferenciou. Assim, na primeira pesquisa, a abordagem realizada permitiu constatar uma clivagem significativa, de natureza geográfica, histórica e cultural, entre o Norte e o Sul do espaço continental; na outra investigação, centrada num objecto empírico muito particular, o sector do turismo, o enfoque analítico privilegiou uma abordagem centrada no desenvolvimento sustentável daquele específico território do Sudoeste do continente português.
Partindo, embora, de motivações distintas, como se verá, as referidas abordagens parecem apresentar uma complementaridade significativa, em relação ao desafio aqui em causa. De algum modo, a primeira investigação como que permitiu enquadrar e contextualizar, em relação a esse desafio, a abordagem seguinte. Em todo o caso, é de sublinhar que não está em causa sintetizar as mencionadas pesquisas, mas fundamentalmente a de procurar ilustrar aquele mesmo desafio. Daí também a ordem de exposição do presente texto: começando por balizar, do ponto de vista analítico, algumas vertentes de abordagem de temas privilegiados em torno das noções de território, património e cultura, será num segundo momento que se entrará mais propriamente na ilustração daquele desafio. No final, teremos, então, a oportunidade de questionar, a partir de algumas questões dilemáticas, a eventual especificidade do Sul do continente português, em particular do ponto de vista da sua necessária sustentabilidade territorial.

\footnotetext{
Professor Catedrático de Sociologia - ISCTE (aposentado). Contacto: matias.ferreira@sapo.pt.

${ }^{1}$ Este texto constituiu a base de uma Comunicação apresentada nas Jornadas de Sociologia Urbana (28 Maio 2008) do Seminário Dinâmicas Urbanas e Território (org. de Luís Baptista) do CESNOVA da Universidade Nova de Lisboa.
} 


\section{Território, Património e Cultura - Um Triângulo de Sustentabilidade}

No quadro de um dos projectos de investigação acima referidos (cf. VMF et al., 2008) ${ }^{2}$, uma das abordagens entretanto privilegiadas centrou-se na problemática do desenvolvimento sustentável e nas condições para uma efectiva sustentabilidade territorial, neste caso do Sudoeste do continente português. Retomemos, então, algumas das perspectivas analíticas que, em parte, acabaram por assumir um papel efectivamente estruturante, não só no desenvolvimento daquelas pesquisas, mas na própria sustentabilidade territorial do objecto da investigação. Como se verá, daquelas perspectivas aparecem especificadas as que mais directamente jogam com o desafio anunciado, em especial em torno do território, do património e da cultura, configurando um triângulo de sustentabilidade da região em causa.

\section{Território e Sustentabilidade}

É um facto que existe hoje uma consensualidade generalizada no sentido de fazer articular, de modo muito estreito, as questões económicas e sociais com a noção de território. Já vai longe, portanto, uma concepção em que o espaço material era, enquanto tal, uma espécie de "terra de ninguém", uma suposta base inerte sobre a qual se admitia, então, uma mera projecção das respectivas actividades económicas e dos correspondentes destinos sociais. Pode-se, assim, admitir que a passagem daquela concepção do espaço material - sobre a qual existe, como sabemos, a longa tradição da Geografia - para a noção de território, corresponde, precisamente, ao momento de mudança paradigmática que coloca aquela noção de território enquanto entidade "socialmente construída" ou, por outras palavras, enquanto componente fundamental da acção da economia e da sociedade.

Dito isto, entende-se porque podemos considerar o quadro problemático do território, da economia e da sociedade - nas suas respectivas especificações analíticas - como uma sistematização paradigmática central, nomeadamente no contexto da referida investigação. Num tal contexto, teve-se presente uma abordagem que jogando com aqueles três vectores analíticos, permitiu um enquadramento empírico da realidade territorial, económica e social do continente português, como forma de ilustrar a problemática de partida. Com efeito, a natureza "construída" do território, no sentido da sua própria transformação por acção da economia e da sociedade, como dissemos, abre-se, assim, para os diversos processos de diferenciação e de segmentação desse mesmo território. Como se sabe, essa abordagem permite, entre outras perspectivas, definir condições de concentração e de dispersão territorial, detectar modalidades de intensa ou difusa urbanização, identificar espaços mais rarefeitos no respectivo povoamento, enfim, avaliar as maiores ou menores assimetrias nas formas de ocupação do território.

Ao fim e ao cabo, estas transformações na organização e no ordenamento territorial são indissociáveis das próprias mudanças económicas e sociais. Com efeito, nas duas últimas décadas, estas mudanças foram muito significativas, em grande medida, no caso português, pela própria integração no quadro institucional e político da União Europeia. Claro que nesse período se acentuaram os processos de globalização e de mundialização, não só da economia, mas também em termos socioculturais, incrementando tendências de padronização nas regras de funcionamento dos mercados económicos e financeiros, mas também no quadro dos modos e estilos de vida social e individual.

Essa tendencial padronização não é, contudo, homogénea, nem os seus efeitos se repercutem, positiva ou negativamente, de igual modo em todo o território. Por isso, a abordagem das assimetrias territoriais, a que corresponde uma perspectiva discriminatória da distribuição de bens e de recursos, não deixa de corresponder a um dos primeiros olhares sobre a segmentação económica e social do respectivo território. Os processos de litoralização e de interioridade do Portugal continental, constituindo uma marca muito forte do povoamento português desde, pelo menos, há mais de quatro décadas, retratam, igualmente, de modo emblemático, aquelas mesmas assimetrias territoriais,

\footnotetext{
$\overline{2}$ Tratou-se de uma investigação, encomendada pelo Turismo de Portugal, sobre Desenvolvimento Turístico Sustentável na Costa Sudoeste do continente português. Esse estudo, coordenado pelo autor deste texto, integrou os seguintes investigadores: Joana Chorincas, Aida Valadas de Lima, Eduardo Limbert, Paulo Lopes Ferreira e Edgar Rocha. Deste modo, muitas das observações a seguir apresentadas reportam-se ao referido relatório final da investigação, sendo por isso de autoria colectiva, ainda que, obviamente, a responsabilidade do que aqui for apresentado seja do redactor deste texto.
} 
como noutro momento tivemos ocasião de ilustrar (cf. VMF, 2007). Significativamente, esta visão mais global, assimétrica, do continente português, como que se "reproduziu" a escalas mais restritas, nomeadamente no contexto da área de estudo da citada investigação, concretamente no Sudoeste do país continental. Recusa-se, contudo, uma visão territorial de tipo dualista, o que não significa ignorar as eventuais especificidades económicas e sociais dos diversos espaços nacionais. Simplesmente, haverá que ter em conta que muitas das eventuais "especificidades" territoriais são resultantes, precisamente, do referido quadro assimétrico.

Mas invocámos atrás outras situações ao nível da organização do território, concretamente em relação às modalidades de concentração ou de dispersão do povoamento e das actividades económicas e sociais. Significativamente, a área de estudo, à sua escala, não deixa de apresentar essa dupla condição territorial, ainda que, em termos comparativos, a um nível bastante rarefeito. Mas, por isso mesmo, a sustentabilidade do território em geral e na área de estudo em particular implica recusar, também aqui, uma visão dualista. Pelo contrário, uma postura de articulação entre espaços mais concentrados e lugares mais dispersos, não só contribui para um maior equilíbrio do ordenamento territorial, como participa, directamente, na própria sustentabilidade do seu desenvolvimento.

O aprofundamento de uma tal postura está de acordo, de resto, com o novo posicionamento sobre os aglomerados urbanos, em que contrariando uma perspectiva tradicional de "rede urbana", hierárquica, vertical e polarizadora, argumenta, antes, a fecundidade das "redes de cidades", enquanto estrutura horizontal, mais equitativa e territorialmente mais equilibrada, ou seja, uma postura assente numa articulação em rede dos aglomerados urbanos, independentemente do seu estatuto administrativo e da sua própria dimensão económica, social e territorial. Como parece evidente, este funcionamento em rede dos aglomerados é indissociável das questões associadas à mobilidade e às acessibilidades, como forma de garantir, em condições materialmente seguras e de qualidade (conforto, custos, etc.), as necessárias ligações entre aqueles aglomerados.

Se as questões das assimetrias territoriais põem directamente em causa os modelos de reordenamento do território, os problemas anteriormente referidos sobre formas de concentração e de dis- persão do povoamento e das actividades, questiona, antes, a necessidade de uma perspectiva de polinucleação dos aglomerados, procurando, assim, como acabámos de ver, uma estrutura em rede dessas diversas implantações territoriais. E, deste modo, é a própria sustentabilidade do território que, em última análise, está aqui em questão.

\section{História e Património}

No quadro territorial que acabámos de assinalar, as referências ao património, independentemente da sua adjectivação pública ou privada, laica ou religiosa, urbana ou rural, etc., são cada vez mais constantes, quer no discurso supostamente erudito, quer nas práticas quotidianas do senso comum. É, realmente, um sinal dos tempos actuais, que também globaliza alguns temas da cultura, ainda que nem sempre seja claro o que é que invocamos, quando falamos de património. Aparentemente, é como se, uma vez mais, estivéssemos todos a falar da mesma coisa ou como se, por estranha coincidência, estivéssemos todos perante a descoberta de um passado, até então "perdido", desde logo no nosso inconsciente colectivo. Contudo, independentemente daqueles equívocos e desta suposta tomada de consciência, é certo que, de modo geral, estamos hoje mais atentos e até mais preocupados com as questões patrimoniais. Por isso mesmo, parece importante avançar nessas questões, procurando alguma clarificação do que possa estar em jogo em torno desse questionamento.

À partida, temos, assim, que a noção de património se organiza, fundamentalmente, através de uma dupla dimensão histórica e cultural, que, de modo estreitamente articulado, configura aquela mesma noção patrimonial. Contudo, um tal enunciado, sendo realmente um ponto de partida, é, enquanto tal, manifestamente insuficiente enquanto identificação, referenciação e projecção desse mesmo património. Por outro lado, aquele mesmo enunciado, tomado de uma forma muito literal, tende a arrastar consigo um efeito politicamente perverso, ao restringir aquela noção a uma visão socialmente particularista e culturalmente isolada, olhando "de longe" e, ao mesmo tempo, mitificando esse mesmo património, como se, ao fim e ao cabo, se tratasse de uma isolada, ainda que importante, "peça de museu". Um tal efeito perverso, que tende à sua multiplicação quase como uma "moda", acaba 
por consolidar, assim, uma visão profundamente restritiva da condição social e política dos processos de produção e de apropriação do referido património (cf. VMF, 1998).

É certo que, tal como sabemos, o património, tomado em termos mais gerais, tem desde logo uma dimensão histórica, mas histórica na medida em que constitui a resultante de múltiplas sedimentações e de diversificados processos, ao longo da sua mais ou menos longa existência. Mas se o património se reduzisse a essa visão histórica - mas uma visão em que, paradoxalmente, a história, propriamente dita, isto é, a história daquelas sedimentações e daqueles processos, acabaria por ficar, necessariamente, como uma visão restrita - em tais condições, aquele mesmo património seria sempre visto como passado, se não mesmo como antepassado. Isto é, como algo inerte na sua antiguidade supostamente majestática e sem possibilidade, assim, de ser plenamente inserido nas dinâmicas económicas e sociais do presente e, no futuro, inexoravelmente remetido a uma simples de peça museográfica, como atrás referimos.

Por outro lado, o património tem também, à evidência, uma dimensão cultural, porque resultante de determinados padrões de cultura, de conjuntos de valores e de representações, de gostos dominantes e de marcas simbólicas, para além do papel ideológico que, explícita ou implicitamente, o património é suposto aglutinar e representar. Mas uma tal diversidade de vectores constitutivos daquela dimensão cultural é, ela própria, mutável, a diversos níveis da sua expressão, na exacta medida em que o magma de cultura em que ela se insere também é mutável, no quadro mais amplo das mudanças societais. Num tal contexto, a dimensão cultural do património, sendo uma das vertentes estruturalmente constitutivas desse mesmo património, não pode deixar de acompanhar e de integrar as próprias mudanças ao nível social e cultural.

História e cultura constituem, deste modo, duas das dimensões fundamentais que identificam e que referenciam, de imediato, aquela noção de património. Mas dimensões que acompanham, como dissemos, os próprios processos históricos e culturais de mudança social e política e, nessa medida, aquelas dimensões recusam uma visão historicista e evolucionista, por um lado, mas também culturalista e elitista, por outro, daqueles mesmos processos de mudança. Razão porque preferimos falar de historicidade, como forma de enfatizar os próprios modelos culturais que, de modo mais implícito do que expressamente assumido, dão sentido e coesão histórica e cultural, não só ao passado e ao presente, mas sobretudo em relação ao futuro desse mesmo património. Num tal enquadramento, a noção de património não pode deixar de ser integrada na própria abordagem da vida quotidiana, social e política como sabemos, não constituindo, portanto, algo de exterior a esse mesmo quotidiano, que eventualmente fosse objecto de "visita" ou que, pura e simplesmente, pudesse vir a ser ignorada!

As observações anteriores podem parecer demasiado banais, se não mesmo redundantes, para quem tem vindo a reflectir sobre as questões do património ou, no extremo oposto, podem parecer demasiado académicas, para quem se interessa, em termos muito operativos, pela preservação e melhoramento do património, independentemente das vertentes históricas e culturais que, como vimos, são constitutivas desse mesmo património. Seria bom admitirmos que, qualquer desses dois tipos extremos de avaliação comporta riscos acrescidos, nomeadamente ao próprio património. Não se tratando de um paradoxo, poderíamos sintetizar esta afirmação no sentido de admitir que uma melhor identificação do património exige uma compreensão dos factores e das dimensões históricas e culturais que o configuram e que uma maior preservação desse mesmo património implica um conhecimento dos contextos e das implicações sociais e políticas que o condicionam.

\section{Cultura e Identidade}

A abordagem anterior do património, que recusa situar esse mesmo património, como dissemos, no "museu da História", não deixa, assim, de o projectar em devir constante, participando activamente nos processos de identificação social e territorial. Por sua vez, estes mesmos processos são passíveis de um melhor entendimento, nomeadamente no quadro de uma matriz de caracterização de uma tipologia identitária. Realmente, tendo em conta que a discussão sobre as identidades socioespaciais, na sua intrínseca condição relacional, só adquire sen- 
tido analítico e pertinência operativa no quadro de determinados sistemas identitários, aquela matriz procura jogar, assim, com quatro grandes entradas desses mesmos sistemas - de escala global e local, por um lado, e dos pontos de vista do sujeito e do objecto, por outro, como noutro momento foi possível aprofundar (cf., nomeadamente, VMF, 2004, pp. 90 ss.). Enquanto matriz sistémica, uma tal abordagem permite caracterizar, portanto, os diversos processos identitários (através de diversas mediações analíticas que não vem ao caso referir), cuja trama relacional configura, precisamente, um determinado modelo cultural. Mas se não faz sentido, no presente contexto, avançar naquelas mediações analíticas, certamente será necessário explicitar devidamente a referida matriz dos sistemas identitários, tomando como referência primeira aquela noção patrimonial. Trata-se de uma matriz tipológica de quatro entradas, como dissemos, dialecticamente agrupadas duas a duas, consoante as escalas de referência ou as perspectivas de abordagem.

No primeiro caso, as escalas global e local constituem, hoje em dia, como sabemos, as duas referências fundamentais do ponto de vista social e territorial. Certamente que não se encontram excluídas, por exemplo, as escalas de nível nacional ou regional. Mas, neste caso, o quadro de referência é de distinta natureza, mais propriamente institucional e administrativa, alheias, portanto, à formulação da cultura e da identidade, enquanto eixo de reflexão analítica e não de mera configuração instrumental. Como suporte conceptual desta dialéctica do global e do local, entre tantos autores, poderíamos citar o posicionamento analítico de M. Castells, quando ele invoca a dialéctica dos "espaços de fluxos", que se situam realmente a um nível global, e dos "espaços de lugares", quando o que está em causa são, efectivamente, os processos ao nível local (cf. M. Castells, 1996, pp. 423 ss.). De sublinhar que esta dialéctica do global e do local tanto se reporta a um nível mais geral - em última instância, no actual contexto dos processos de globalização - como pode ter uma aplicação a níveis mais específicos, isto é, mais "localizados", independentemente das dimensões quantitativas em jogo.

Mas a referida matriz também privilegia uma outra dialéctica, agora em torno das perspectivas do sujeito e do objecto. Se o relacionamento sisté- mico anterior põe em debate a questão das escalas de referenciação das relações sociais e espaciais, agora trata-se de questionar, digamos de uma forma elementar, "quem" se relaciona com "quê", ou seja, procura relacionar, realmente, a dialéctica que contrapõe uma pluralidade de sujeitos face a uma multiplicidade de objectos. E se aquela pluralidade implica uma manifesta diferenciação social e cultural dos sujeitos, esta multiplicidade desdobra os objectos em diversos tipos que, esquematicamente, os poderíamos associar consoante a sua projecção basicamente produtiva ou, reciprocamente, de acordo com a sua condição de se inserirem em processos de apropriação social e espacial. Não vindo, portanto, ao caso avançar nas diversas mediações analíticas que a referida matriz sistémica determina - mas sublinhando que não estamos perante situações identitariamente imutáveis, nem sequer se poderá invocar uma qualquer "essência" em relação ao sistema de identidades naqueles espaços - constatamos, assim, que o quadro matricial invocado permite entender a profunda e heterogénea complexidade relacional do próprio sistema de identidades sociais e espaciais.

Território, património e cultura foram, assim, as três áreas temáticas fundamentais, no contexto analítico aqui em debate, que permitiram configurar um triângulo de sustentabilidade, neste caso reportado ao desafio de partida. É altura, portanto, de avançarmos neste caminho, de Lisboa para Sul, à procura da sua eventual especificidade e, nessa mesma caminhada, abrir espaço para a discussão sobre a necessária sustentabilidade do território entretanto percorrido.

\section{O Sul como Paradigma Histórico, Cultural e Territorial}

\section{Lisboa, Finisterra Atlântica \\ e Matriz Mediterrânea}

Como forma de ilustrar alguns dos pressupostos que permitem sustentar, realmente, a afirmação do Sul como paradigma histórico, cultural e territorial, comecemos por retomar algumas das observações que nos permitem partir "de Lisboa para Sul”, aliás no seguimento de um específico 
projecto de pesquisa, que referimos no início (cf. VMF, 2002) ${ }^{3}$. Trata-se, realmente, de uma partida, que nos obrigará, contudo, a alguma identificação do lugar de origem dessa viagem.

À partida, portanto - ou melhor, como primeira visão - temos Lisboa enquanto cidade de água, na sua estreita relação com o mar urbano que lhe esteve na origem e que lhe conferiu uma identidade muito específica, tal como noutros momentos tivemos ocasião de destacar ${ }^{4}$. Esta mesma condição, pela força da sua materialidade e pelo projecto identitário que representa (ou que pode vir a representar) no imaginário urbano e metropolitano de Lisboa, constitui, sem dúvida, um primeiro (e imediato) olhar de apresentação e de representação de Lisboa.

Recordemos então, sucintamente, a trilogia analítica que sustenta esta fundamental condição de Lisboa. Com efeito, partindo da constatação que as frentes de água de cidades marítimas ou fluviais constituem os próprios paradigmas das cidades de água, aquela trilogia abre-se, assim, para uma fronteira territorial (que não deve ser vista propriamente como um "obstáculo"), configurando uma determinada simbologia identitária e assumindo uma projecção histórico-cultural, num conjunto de dimensões que, globalmente, permitem uma caracterização determinante daquelas frentes de água.

Dimensões articuladas entre si, naturalmente, em cujo contexto são tecidos os laços patrimoniais das cidades históricas e portanto, também, da cidade de Lisboa. Justificámos uma tal afirmação recordando igualmente que muito embora as cidades históricas, marítimas ou fluviais, tenham atravessado, muitas vezes, situações de crise, sobretudo no quadro económico e político, o mesmo não terá acontecido ao nível da sua própria identidade histórica e cultural, cuja perenidade acabou por sedimentar e projectar os traços patrimoniais, identitários realmente, daquelas mesmas cidades históricas. Uma tal materialidade imagética, levou- -nos mesmo a questionar se aquele mar urbano e metropolitano, que identifica e que simboliza esta "cidade de duas margens", não constitui (ou poderá vir a constituir) um dos próprios fundamentos do imaginário da Metrópole de Lisboa.

Mas a cidade de água de Lisboa tem, ainda, uma dupla condicionante histórica e cultural, na medida em que ela se constituiu, simultaneamente (?), como uma cidade atlântica, ainda que de matriz mediterrânea. Assim, aquelas condicionantes, sobretudo de ordem histórica e geográfica, conferem à cidade de Lisboa um quadro societal bastante heterogéneo, agregando assim, numa "mistura" complexa, múltiplos e variados comportamentos individuais, distintos modos e estilos de vida social e diferenciadas referências culturais, que no referido magma societal acabam por se assumir como bastante atípicos para qualquer um dos respectivos modelos de civilização urbana, tomados isoladamente.

Efectivamente, Lisboa, como cidade atlântica, é, em termos metafóricos, como uma personagem à beira de uma ravina, pronta a "partir" ou a "chorar" os que já partiram! É, sem dúvida, uma frágil condição: aparentemente, só existe em situação de ruptura, como se "tanto mar fosse demais..."! Mas uma tal situação de finisterra (adiante voltaremos a este ponto) é também uma marca territorial, uma referência identitária, naquela fragilidade de partir e de ficar. A pulsão da partida confronta-se, assim, com a atracção das suas raízes identitárias. Lisboa atlântica tem, portanto, esta "ondulação" de partir e de regressar, como se fosse uma "terra de ninguém”, em que as ondas marítimas, participando naquela identificação territorial, imprimem um movimento de abandono, de volúpia e de reconquista! Numa tal alegoria, está implícito ainda o "desígnio" da emigração além-atlântico, que quase sempre se projecta com o desejo do regresso..., mesmo que, em muitos casos, ele acabe por não se cumprir!

Mas Lisboa é também, ainda que de modo

\footnotetext{
O texto em referência constituiu uma versão simplificada de uma "nota de intenção", enquanto documento inicial (que acabou por não ter seguimento) para uma Exposição sobre Lisboa no Parc la Villette em Paris (2003). Correspondeu assim a um documento base, a convite daquela instituição, a partir do qual fosse então possível dar a ver, expor precisamente a cidade de Lisboa. Como se compreenderá, a lógica discursiva daquele documento (que sem dúvida acabou por se reflectir no texto entretanto publicado), procurou seguir a própria lógica de um guião de exposição, neste caso da cidade de Lisboa, o que, como sabemos, não é necessariamente coincidente com a "exposição" de uma específica abordagem analítica. Deste modo, enquanto guião de uma exposição, estará mais centrado num quadro metodológico expositivo, do que na explanação de diversos materiais empíricos justificativos de uma eventual opção analítica.

${ }^{4}$ Uma das primeiras referências do autor deste texto à abordagem das cidades de água reporta-se a uma comunicação apresentada no Colóquio Comemorativo dos 450 anos da Cidade de Ponta Delgada (Universidade dos Açores, Março de 1997). Por outro lado, essa mesma comunicação acabou por desenvolver um texto inicial, apresentado no Festival do Imaginário (Associação Palha de Abrantes, Abrantes, Novembro de 1996). Finalmente, uma versão ligeiramente reformulada e desenvolvida, foi publicada em 1998 e, mais tarde, integrada numa nova publicação do autor (cf. VMF, 2004).
} 
mais difuso, uma cidade mediterrânea, pelo seu clima, pela sua luz e, sobretudo, pela sua cultura. Uma tal percepção é mais evidente na subtileza dos seus materiais e das suas cores, no delineado do edificado e do tecido urbano, na confecção dos seus sabores e na oscilação dos seus humores, enfim, muito mais visível na própria cultura material do que no quadro dos comportamentos sociais, demasiado "confundidos" e em parte integrados nos fluxos permanentes de "outras gentes", dada a grande abertura cultural da cidade ao "exterior" e aos forasteiros, não tanto por influências estritamente turísticas, mas em grande medida por razões económicas e sociais.

Mas de onde vem, então, esta dupla condição societal urbana, histórica e cultural - numa dialéctica desigual, certamente - veiculada pelo que poderíamos considerar como uma certa "dominação" atlântica, mas também, num outro plano, pelo que sem dúvida constitui uma espécie de "resistência" mediterrânea? No contexto do continente português e tendo em conta o próprio quadro civilizacional e cultural em que ele se insere, é possível registar uma demarcação territorial bastante precisa, que como é óbvio não é exclusivamente de ordem física, entre o norte e o sul do país continental. É uma tal demarcação que nos permite sustentar a influência de uma cultura atlântica, sobretudo no norte do país, enquanto que, no sul, uma tal influência se reporta, dominantemente, a uma cultura mediterrânea, sobretudo de matriz islâmica.

Historiadores, como José Mattoso, geógrafos, como Orlando Ribeiro, arqueólogos, como Cláudio Torres, entre outros, ajudam-nos a estabelecer aquela demarcação, colocando a cidade de Lisboa, de certo modo, num espaço central de mediação entre aquela dupla influência civilizacional. A este nível, portanto, tais influências foram plasmadas, certamente, pelas respectivas componentes religiosas, o que levou José Mattoso a afirmar que aquela demarcação, não implicando uma diferenciação exclusiva, ficou marcada por duas importantes formações político-religiosas, a cristã e a islâmica e, mais tarde, também pela formação judaica (J. Mattoso et al., 1992). E muito embora, ainda segundo o mesmo autor, a partir de 1147, com a Reconquista de Lisboa aos Árabes, aquelas influências religiosas se tenham podido alargar para outras crenças, sabemos que, ao fim e ao cabo, a religião judaico-cristã acabará por ser dominante, ainda que com graduações e modalidades de certo modo distintas, a norte e a sul do país continental.

Trata-se, pois, de uma demarcação com profundas raízes culturais e civilizacionais e cuja expressão geográfica aparece relativamente bem delineada. Orlando Ribeiro estabeleceu com rigor essa demarcação que, sob o ponto de vista físico, desenha uma "fronteira" oblíqua em pleno centro do continente português, ao longo do rio Mondego. Realmente, "o Mondego pode considerar-se o limite entre as duas regiões assim demarcadas. Ao Sul deste rio, o domínio árabe foi mais duradouro e profundo, a reconquista mais tardia e lenta: aqui começa o Portugal feito já em parte pelos portugueses do Norte, que deles tomou as instituições, os usos, a língua e algumas tintas de uniformidade. Contraste de civilização, contraste de clima e de paisagens" (O. Ribeiro, 1945, 90). Em páginas anteriores, o autor era ainda mais explícito quando afirmava que "o contraste entre as serranias e fundos vales do norte e os monótonos plainos meridionais condiciona duas vocações humanas. De um lado, o isolamento e o localismo de uma população densa, ensimesmada e esparsa, onde apenas se inscreve uma forte acção histórica - a romana; do outro, caminhos fáceis e abertos, gente pouco numerosa em grandes núcleos afastados. Foi sempre aqui a larga porta de entrada de todas as influências culturais mediterrâneas (...)" (op. cit., 86). E, sem dúvida, acrescentaríamos nós, Lisboa não deixou de constituir uma dessas portas de entrada, não só daquela influência mediterrânea, mas, ao fim e ao cabo, daquela dupla corrente civilizacional!

Esta mesma constatação vai ao encontro do posicionamento apresentado pelo historiador e arqueólogo Cláudio Torres, ao acentuar, no quadro dos encontros, mas também dos desencontros de diversas civilizações, um conjunto significativo de consequências da demarcação territorial acima mencionada, mas agora no próprio contexto da Península Ibérica. Assim, aquele maciço montanhoso "que muitos geógrafos romanos chegavam a imaginar como um prolongamento dos Pirinéus" (...) define uma grande fronteira natural entre o Norte e o Sul da Península Ibérica. É uma barreira (...) atravessada em quatro pontos principais, abertos desde sempre aos movimentos militares e às caravanas de almocreves". E se cada uma destas "quatro grandes passagens-porto" irá constituir "a espinha dorsal das quatro nações medievais que 
decidirão o futuro político da Península" (recordadas pelo autor como constituindo os reinos de Aragão, Castela, Leão e Portugal), aquela quarta e última passagem liga, precisamente, "os caminhos da Galiza à via de Lisboa-Santarém” (C. Torres, 1992, 364), estando assim na origem da formação do reino de Portugal.

Porta de "entrada, "passagem-porto", como não ver, então, Lisboa, enquanto referente histórico e cultural, como mediação territorial naquela dupla influência civilizacional, atlântica e mediterrânea, em cujas origens ancestrais a geografia terá tido, portanto, um papel determinante? Por outro lado, uma tal influência é largamente ilustrada através das "narrações" (cuja fiabilidade histórica não parece estar em causa) dos Cruzados Osberno e Arnulfo (1936), aquando da conquista de Lisboa, depois de uma longa permanência árabe (mais de quatrocentos anos) nesse mesmo lugar. Poderemos admitir, certamente, alguma fantasia testemunhal por parte daqueles narradores, quando transcrevem supostos diálogos entre os sitiados e os conquistadores, mas não interessando, para o que aqui está em causa, discutir esses graus de veracidade, as observações que acabam por ser relevantes são, precisamente, as que se reportam aos conteúdos culturais e civilizacionais daquele confronto (cuja leitura se aconselha vivamente). Nessa medida, aquelas "narrações", enquanto referência documental e iconográfica, ajudam-nos a compreender a referida matriz de duas culturas originalmente bem distintas entre si, que embora não exclusivas estão presentes em múltiplas formulações linguísticas, no quadro de valores, comportamentos e representações sociais, no domínio das crenças e dos "destinos", enfim, numa simbiose cultural que, contudo, se torna hoje difícil destrinçar da sua matriz original.

Num tal contexto, aquelas múltiplas influências culturais exprimem-se, do ponto de vista social, de modo relativamente subtil como já o afirmámos, estando profundamente interiorizadas algures num "inconsciente colectivo" de Lisboa. Ou, por outras palavras, em diversas zonas da cidade são sobretudo as "pedras", isto é, o quadro edificado, o alinhamento das vias, o próprio tecido urbano, para além de uma infinidade de elementos ditos monumentais, que acabam por ilustrar aquelas diferenciadas influências culturais, de resto testemunhadas por sucessivas descobertas arqueológicas. Ao fim e ao cabo e à semelhança do que referimos a propósito das supostas crises identitárias das cidades de água, também a este nível a ambivalência civilizacional, atlântica e mediterrânea de Lisboa, continua a alimentar a própria matriz cultural da cidade, para além de uma certa "anomia" do presente e de eventuais vicissitudes do seu futuro.

Mas Lisboa situa-se também, já o dissemos, numa finisterra, num território de "fronteira", atlântica sobretudo do ponto de vista geográfico (a não identificar com a geografia física), mas também, como acabámos de ver, mediterrânea no sentido de uma específica demarcação histórica e cultural. Por isso, Lisboa confronta-se com diversas "fronteiras": materiais, nesta condição de finisterra; simbólicas, no paradigma das suas frentes de água oceânica, marítima e fluvial; imaginárias, nos processos identitários de uma cidade de "duas margens". Uma "fronteira" que condensa, ao fim e ao cabo, aquela condição terrestre com a projecção aquática da cidade, numa simbiose da terra com a água, em que a condição histórica e cultural de "partir" e de "voltar" se constitui, em última instância, como uma metáfora de quem vive, efectivamente, numa terra finita - isto é, onde a terra acaba... e o mar começa, realmente!

Mas havíamos prometido partir de Lisboa para Sul. É altura, portanto, de entrar propriamente nesse território, ainda que nos fiquemos, por agora, no espaço mais específico do Sudoeste. É, sem dúvida, uma mudança de paisagem e, como veremos, é também uma mudança de registo analítico, não por razões históricas e culturais - cujas referências fundamentais naturalmente se mantêm - mas sobretudo por vicissitudes de diferentes lógicas dos processos de investigação.

\section{A Especificidade do Sudoeste no Continente Português}

No quadro do projecto anteriormente referido (VMF, 2008 et al.), a investigação desenvolvida centrou-se, como já indicámos, no sector do turismo na Costa Sudoeste do continente português. Como é evidente, não iremos sumariar as pesquisas entretanto realizadas, mas tão só, tendo em conta o desafio a que nos obrigámos, destacar os elementos empíricos ilustrativos desse mesmo desafio. Mas sublinhe-se, desde já, uma condição fundamental do estudo realizado, que implicou que toda a investigação se tenha inserido numa abordagem do res- 
pectivo desenvolvimento sustentável, naturalmente orientada para o respectivo objecto de estudo. Em última instância, será a própria sustentabilidade, em diversas dimensões analíticas, que aqui estará em discussão.

Das diversas abordagens temáticas que o projecto privilegiou, retenhamos, então, de modo necessariamente sucinto, algumas das áreas de análise $^{5}$ que mais directamente se articulam com o que aqui está em causa. Um tal exercício poderá vir a ajudar-nos, no final da presente exposição, ao questionamento do desafio de partida. Como é evidente, o nosso ponto de chegada não será nem conclusivo, nem definitivo, mas antes, assim se espera, ilustrativo daquele mesmo desafio.

\section{Território e Economia}

\section{Síntese Retrospectiva}

A Costa Sudoeste de Portugal é constituída pelos concelhos de Alcácer do Sal, Grândola, Santiago do Cacém, Sines e Odemira, do Alentejo Litoral, e pelos concelhos da Costa Vicentina, Aljezur e Vila do Bispo. A proximidade territorial da Região Metropolitana de Lisboa, a contiguidade espacial com o Algarve, a extensa orla marítima e a relativa proximidade a Espanha, colocam a Costa Sudoeste numa posição privilegiada, num quadro de articulação nacional e transnacional. Este posicionamento geográfico particular determina a inserção natural da região num território de confluência do "Arco Atlântico" e do "Arco Latino/Mediterrâneo Ocidental" que integram o vasto "Sudoeste Europeu" e a "Diagonal Continental" que se estende até ao Atlântico - o que, numa outra linguagem, vai ao encontro do posicionamento apresentado no subcapítulo anterior.

Com pouco mais de cento e dez mil habitantes (2001), cerca de três quartos dessa população reside em áreas urbanas que ocupam pouco mais de metade do território em causa. Os concelhos da Costa Vicentina são aqueles que apresentam um menor cariz urbano. É sobretudo no Alentejo Litoral que se encontra uma dinâmica mais urbana, inclusive no quadro da própria região alentejana. Mas, efectivamente, o território, no seu todo, não apresenta uma estrutura urbana equilibrada, encontrando-se a maioria da população concentrada num número muito reduzido de centros urbanos de média e pequena dimensão, sendo Sines o único lugar com mais de dez mil habitantes. Contudo, em termos demográficos, a situação da região é preocupante. Desde 1960 que tem vindo a perder população. A reduzida densidade populacional, que caracteriza este território desde há séculos, tem também vindo, assim, a diminuir significativamente em todos os concelhos, com excepção de Sines. Uma tal situação é consequência, quer do resultado negativo do balanço entre nascimentos e óbitos quer, correlativamente, dos movimentos migratórios que têm por destino o estrangeiro ou áreas nacionais mais atractivas, sobretudo do ponto de vista económico.

A região contribui para pouco mais de $1 \%$ do Produto Interno Bruto (PIB) do País, indicador que é notoriamente empolado pelo caso de Sines. Com efeito, este concelho, a par da Grande Lisboa e do Grande Porto, forma o conjunto restrito de territórios com um PIB per capita superior à média nacional, que, efectivamente, se deve à existência do pólo urbano-industrial de Sines, com uma especialização na fileira da petroquímica. O território do Sudoeste regista uma baixa taxa de actividade da população residente (cerca de 52\%). O desemprego atinge os $9 \%$ da população activa, tendo-se registado nos últimos anos um agravamento deste problema social na região, em particular nos concelhos mais marcadamente rurais. No entanto, este território, comparativamente com as restantes subregiões do Alentejo e do Algarve, apresenta um menor volume relativo de desempregados na faixa etária mais jovem.

\footnotetext{
5 Já anteriormente sublinhámos que estamos perante um estudo de autoria colectiva, pelo que as observações que se seguem não deixarão de se fundamentar nas diversas pesquisas realizadas pelo conjunto de investigadores atrás identificados. É justo, contudo, reconhecer que para cada uma das áreas temáticas privilegiadas pelo projecto, se verificou uma determinada especialização de abordagens, consoante o respectivo domínio disciplinar dos membros da equipa de investigação. Na abordagem específica aqui em discussão, é de destacar que, na área do território e da economia, Joana Chorincas foi a investigadora principal, enquanto que em relação ao património e cultura, foi o coordenador do estudo que teve essa incumbência. Embora não seja aqui abordada (como justificaremos adiante), é de referir que em relação à área do Ambiente e dos Recursos Naturais, a investigação principal esteve a cargo de Eduardo Limbert. Em todo o caso, não será demais sublinhar que toda a equipa de investigação participou e é solidária nos resultados finais apresentados, sendo que, no presente texto, essa responsabilidade só pode vir a ser imputada, naturalmente, ao respectivo redactor.
} 


\section{Prospectiva e Sustentabilidade}

Numa abordagem tendencialmente prospectiva, poderemos sintetizar um certo número de condições que de algum modo identificam o território em observação. Desde logo o triângulo urbano Sines/Santiago do Cacém/Santo André constitui uma centralidade fundamental do Alentejo Litoral. A importância deste triângulo configura-o como uma aglomeração urbano-industrial com fortes potencialidades de desenvolvimento futuro. Assim, esta aglomeração poderá vir a ter um papel relevante do ponto de vista da massa crítica de um "pólo" territorialmente ordenado, economicamente equilibrado e com um projecto de desenvolvimento urbano específico, no contexto da Costa Sudoeste.

A par da presença daquela importante aglomeração, a Costa Sudoeste é ainda marcada por uma forte ruralidade, o que lhe confere uma acentuada dualidade: cerca de metade deste território é "predominantemente rural", ao mesmo tempo que $72 \%$ da população vive em áreas urbanas. Em todo o caso, a ruralidade da região é muito acentuada, com um povoamento muito disperso e muito rarefeito (e parece possível admitir que essa dispersão rural tem uma correlação positiva elevada com o próprio envelhecimento acentuado da população no seu conjunto).

A Costa Sudoeste apresenta uma elevada especialização num conjunto reduzido de actividades, com destaque para as indústrias pesadas ligadas ao complexo de Sines e para a agricultura de especialidade concentrada sobretudo nos concelhos de Odemira, Alcácer do Sal e Grândola (reveste-se de elevada importância todo o perímetro de rega do Mira, em Odemira). Deste modo, os investimentos no sector industrial e de produção de energia em curso - com um destaque particular para as energias renováveis - a par dos que se perspectivam na plataforma portuário-industrial de Sines, bem como os investimentos no sector turístico na faixa litoral mas também no interior daquela região, dão forma a importantes transformações económicas e territoriais, que poderão conduzir a um reforço da posição da Costa do Sudoeste e em especial dos seus eixos mais dinâmicos, no conjunto da economia regional e nacional.

Em síntese ${ }^{6}$, é possível constatar a existência no Sudoeste (através de um exercício de clusteri$z a c ̧ a \tilde{o}$ realizado para o conjunto da região) de dois grupos territoriais fundamentais, sendo que num deles é possível ainda autonomizar um terceiro caso. Concretamente, um grupo reunindo os concelhos de Sines, Santiago do Cacém, Alcácer do Sal e Grândola-agregando os concelhos que apresentam níveis de desenvolvimento urbano mais elevados, com maior dinamismo do ponto de vista económico e dos investimentos previstos; e um segundo grupo envolvendo os concelhos de Odemira, Aljezur e Vila do Bispo - reunindo os concelhos com maiores características de ruralidade e interioridade, em virtude da menor dinâmica demográfica e económica. Contudo, Odemira funciona como uma "zona de transição" da Costa Sudoeste, definindo a fronteira entre o norte da região (primeiro grupo) e o sul (os restantes concelhos) e constituindo, assim, uma distinta formação territorial.

\section{Património e Cultura}

\section{Síntese Retrospectiva}

Do ponto de vista cultural (no sentido socioantropológico do termo), a Costa Sudoeste apresenta significativas diferenças que, em última análise, terão a ver com a história do seu povoamento (romanos, árabes, judeus, cristãos...), com as diversas economias locais (que procuram assumir, no actual contexto de progressiva globalização, uma especificidade particular), mas também com a geografia, nomeadamente a decorrente de uma cultura atlântica, de matriz urbana (até pela proximidade significativa da região metropolitana de Lisboa e de centros urbanos de média dimensão). Mas esta

\footnotetext{
${ }^{6}$ Uma das áreas fundamentais da investigação centrou-se, naturalmente, tendo em conta a qualidade ecológica da região em causa, no Ambiente e Recursos Naturais. Por razões de espaço, mas também em virtude dos objectivos deste texto, essa área central não será aqui abordada. Recorda-se, entretanto, de modo muito esquemático, os elementos fundamentais daquela área no Sudoeste. Com efeito, a Costa Sudoeste apresenta uma qualidade ecológica e ambiental e uma diversidade paisagística particularmente notáveis, que o próprio senso comum reconhece e que a investigação realizada teve a oportunidade de demonstrar. Percebe-se, portanto, que essa qualidade e diversidade integrem um vasto conjunto de áreas protegidas. Assinalemos, então, a existência do Parque Natural do Sudoeste Alentejano e Costa Vicentina (PNSACV) e de duas Reservas Naturais: a Reserva Natural do Estuário do Sado e a Reserva Natural das Lagoas de Santo André e da Sancha. Enquanto espaços protegidos, há a assinalar, ainda, diversas áreas integradas na Rede Natura 2000.
} 
condicionante geocultural não é única: com efeito, numa perspectiva culturalmente complementar (que não necessariamente oposta), aquela área é ainda fortemente tributária de uma histórica e económica influência mediterrânica, genericamente presente em toda a costa, ainda que mais visível à medida que caminhamos para sul desse mesmo território.

Tais diferenças históricas, económicas e geográficas - e portanto culturais - vão a par com certas distinções que, em última análise, especificam e diferenciam, àquele nível, o território em causa. Um tal processo de diferenciação permitiu-nos reforçar a demarcação territorial anteriormente assinalada: concretamente, entre um território que a partir do estuário do Sado se expande até à zona de Sines e de Santiago do Cacém, por um lado, e, por outro, o espaço que vai de Odemira até Vila do Bispo. Mas Odemira, como dissemos, parece ser menos uma "fronteira" e muito mais um território de transição, no limite não pertencendo a nenhuma daquelas subáreas, tal como já havíamos visto (no ponto anterior) ao nível propriamente territorial. Não será por acaso que administrativamente pertence, ainda, ao distrito de Beja - como que a assinalar, emblematicamente, a sua pertença a uma região bem demarcada, o Alentejo - mas transição ainda (talvez devido à sua dimensão proporcionalmente "excessiva") entre a ampla e dominante planura alentejana e um litoral atlântico relativamente ameno (em comparação com a restante costa na região centro e norte do país).

São portanto essas sedimentações históricas e essas diferenciações geográficas que acabaram por identificar o património cultural do Sudoeste, mesmo sabendo que outras dimensões patrimoniais e culturais são igualmente constitutivas daquele território. Num tal contexto, um indicador cultural, sem dúvida significativo, será o que tipifica o património edificado, nomeadamente o religioso. Já do ponto de vista do património originariamente com fins militares e defensivos, seria natural encontrar diversas edificações, uma vez que se trata de um território de frente com o Atlântico. Mas também aqui a sua distribuição não é homogénea. Ainda no quadro do património cultural, é possível distinguir diversos tipos, não só o património edificado e/ou arquitectónico, para além, obviamente, do próprio património urbano. Sob o ponto de vista do patri- mónio de natureza arqueológica, a longa história da região, com as suas sucessivas sedimentações civilizacionais, acabaram por determinar a existência de uma cultura ancestral, na generalidade ao longo de todo esse território.

Mas o património cultural não se esgota nas situações anteriormente referidas. Ele espelha-se, igualmente, em manifestações diversas, como sejam o artesanato, a gastronomia e as festas, feiras e romarias. É sem dúvida significativo assinalar que estas manifestações culturais, em particular as duas primeiras, acabam por seguir, de algum modo, uma diferenciação territorial significativa, diferenciando, assim, as situações da costa, da planície e da serra. Para além desta diferenciação, digamos transversal ao Sudoeste, é necessário fazer uma nova distinção, genericamente entre o norte e o sul dessa área, retomando, então, as subáreas atrás assinaladas - a que envolve os concelhos a norte, desde Alcácer e Grândola até Sines e Santiago do Cacém, por um lado, e os restantes concelhos de Odemira, Aljezur e Vila do Bispo, por outro. Claro que nestes dois últimos concelhos já estamos no Algarve e uma tal situação irá introduzir, necessariamente, formas combinadas ou integradas na respectiva identidade cultural, passíveis de identificação em múltiplos elementos patrimoniais.

Numa procura de especificação patrimonial e cultural no interior do Sudoeste, foi possível diferenciar diversos tipos, a que corresponderam outras tantas manchas territoriais distintas (a través da agregação de freguesias) e que, no seu conjunto, constituem como que um puzzle identitário da Costa Sudoeste do Continente. Essas zonas aparecem identificadas segundo a respectiva articulação consoante a maior ou menor proximidade do mar (litoral, planície e interior), mas também de acordo com a sua localização geográfica (norte, centro e sul). O que permitiu construir uma tipologia de situações patrimonialmente significativas.

\section{Prospectiva e Sustentabilidade}

Num contexto de permanências e de mudanças patrimoniais e culturais no Sudoeste, será certamente importante tentar avaliar, de forma sucinta, alguns dos elementos mais significativos do posicionamento anterior. Não se trata, propriamente, de 
uma síntese da investigação realizada, mas antes de um conjunto de observações tendencialmente prospectivas sobre as próprias condições identitárias e culturais da região de estudo.

Desde logo é possível constatar que a região do Sudoeste é, historicamente, um mosaico muito diversificado e ancestralmente sedimentado de múltiplas culturas e civilizações que ocuparam e povoaram, ao longo de séculos, a generalidade daquele território. Contudo, essa multiculturalidade civilizacional está, hoje, socialmente muito diluída, em grande medida devido ao peso hegemónico de uma "modernidade" tardia que importou valores e orientações muito pouco integrantes, se não mesmo contraditórios, com aquele magma civilizacional. Assim, se aquela identidade histórica e cultural é, sem dúvida, uma marca muito forte daquela região, a sua "invisibilidade" empírica e a sua "normalização" contemporânea introduzem uma fragilidade territorial e uma anomia cultural muito acentuadas.

Naquele quadro histórico e cultural, a diversidade e a qualidade do património edificado, nas suas múltiplas dimensões de arquitectura civil, militar e religiosa, a que deveremos acrescentar diversas manifestações artísticas, nomeadamente de arte sacra, a par do próprio património etnográfico e arqueológico, constituem, globalmente, pontos muito fortes do património e da cultura do território em causa. Contudo, confirma-se uma ainda que não generalizada degradação desse património, ao mesmo tempo que se constata uma acentuada insuficiência documental e bibliográfica, resultante de uma escassa investigação científica e de alguma menorização pública de boa parte desses elementos patrimoniais. O resultado não deixa de ser paradoxal, pois face àquela riqueza patrimonial, verifica-se, assim, uma fraca visibilidade externa daqueles mesmos valores culturais.

Ainda que muito parcelizada e territorialmente um tanto dispersa, é possível individualizar certas manifestações de cultura local, sobretudo em espaços de tendencial ruralidade. Concretamente, no quadro da gastronomia e do artesanato, mas também em relação a certas festividades, na generalidade associadas a eventos de carácter religioso, encontram-se, ainda, diversas manifestações de uma cultura geográfica e temporalmente localizada. É certo que a região apresenta igualmente alguns eventos de carácter nacional (ou mesmo internacional), como sejam o Festival Músicas do Mundo (em Sines) e o Festival do Sudoeste (em Zambujeira do Mar). Mas aparte essa projecção para além da área de estudo, aquele "localismo" cultural é acompanhado de uma ausência de dispositivos de sinalização e de interpretação das respectivas manifestações culturais, para além do seu próprio fechamento nos respectivos contextos comunitários.

Em termos gerais ou, noutros termos, no quadro dos processos identitários, a região do Sudoeste apresenta, portanto, valores patrimoniais e culturais bastante significativos, em termos quantitativos e qualitativos. No entanto, a ausência de políticas culturalmente orientadas, sobretudo ao nível regional e local, a par de uma insuficiência de competências de recursos humanos na esfera patrimonial e, mais amplamente, no domínio cultural, deixam a região em causa numa situação de amplas fragilidades. Mas fragilidades acrescidas, uma vez tratar-se de um território sob fortes pressões de natureza turística e cuja sustentabilidade o "mercado", só por si, não oferece garantias, mínimas que sejam. Ao fim e ao cabo, a cultura patrimonial do Sudoeste é um bem em si mesmo não renovável, se não for passível de integração sustentável nas restantes políticas económicas, sociais e ambientais.

Em última instância, as observações anteriores não deixaram de destacar aspectos e situações que, do ponto de vista patrimonial e cultural, apresentam uma perenidade assinalável no Sudoeste, a par de outros mais sujeitos a processos de alteração ou mesmo de transformação. É certo que a condição patrimonial e cultural de um determinado território tem tendência, na generalidade dos casos, a uma inércia de manutenção do seu próprio status, sem que isso implique uma imutabilidade permanente e definitiva. Também sabemos que a acontecer mudanças, de maior ou menor significado, elas têm origem sobretudo em factores exógenos, exteriores portanto àquelas condições de tendencial conservação cultural. E sem dúvida que as actividades turísticas, em geral, têm impacto, positivo e negativo, naquelas condições. O que significa, como já foi sublinhado, que também a este nível patrimonial e cultural se coloca uma questão de sustentabilidade, no quadro interactivo entre uma determinada condição patrimonial das comunidades de origem e as múltiplas influências exteriores a esses quadros comunitários. 


\section{A Especificidade do Sul - e a sua Sustentabilidade?}

É altura de rematar esta comunicação. Lembremo-nos que partimos de um desafio - não de uma tese, que exigiria outro tipo de fundamentação - sobre a especificidade histórica e territorial do Sul do continente. $\mathrm{E}$ a questão de fundo que se coloca, tal como a enunciámos no início, é de nos interrogarmos sobre a eventual sustentabilidade desse mesmo território. $\mathrm{O}$ que nos obriga a recordar, ainda que de modo muito simplificado, a problemática do desenvolvimento sustentável. Realmente, como destacámos à partida, o estudo sobre o Sudoeste foi desenvolvido à luz desse mesmo paradigma, em que o Sudoeste acabou por se constituir como um significativo "laboratório de ensaio" de muitos dos eixos que problematizam esse paradigma.

E, no entanto, o desenvolvimento sustentável tal como a sustentabilidade territorial, não parecem encontrar consensualidade nas suas definições, nos seus conteúdos conceptuais e operativos e nas suas próprias aplicações, o que certamente abre um campo de ambiguidades, desde logo, nas respectivas propostas políticas. Perante um tal quadro analítico ainda tão difuso, aceitemos, então, o desenvolvimento sustentável na sua definição minimalista, oriunda do Relatório Brundtland (1987), que, na sua extrema simplicidade, pode ser entendido como um posicionamento ético do desenvolvimento, ao defender que (simplifico) a actual utilização dos recursos e do ambiente não deve hipotecar a sua utilização pelas gerações futuras. Independentemente das ambiguidades, aquela atitude normativa tem vindo a orientar a "agenda política" do ambiente e do território, quer na feitura de documentos oficiais, quer nas propostas e recomendações de carácter político, em que aquela ambiguidade conceptual e operativa não tem estado isenta de consequências contraditórias ao nível das políticas ambientais e territoriais, sobretudo à escala global do planeta.

Como sabemos, a problematização do desenvolvimento sustentável teve origem, antes de mais, no debate sobre o ambiente. Sem dúvida que as duas últimas décadas foram decisivas para criar uma "consciência ambiental", tal como os anos 70 do século passado, constituíram o período de maturação de uma "consciência ecológica", como vimos noutro momento (cf. VMF, 2002). Uma tal "interiorização" da questão ambiental, também em relação às cidades e aos territórios, tem implicado uma progressiva assunção do ambiente nas políticas públicas, nas suas diversas vertentes e em distintos sectores, aos vários níveis da sua actuação. Por isso, foi importante admitir, inclusivamente no quadro da estrutura estatal - aliás na esteira de muitas directivas de âmbito europeu - que tais políticas ambientais não dispensavam a sua necessária articulação com a problemática do ordenamento territorial e, portanto, também com o ordenamento das cidades. Nessa medida, a articulação institucional entre o ambiente e o ordenamento deveria permitir uma maior aproximação à problemática da sustentabilidade, desde que as práticas políticas não ficassem demasiado dependentes e hegemonizadas, precisamente, por essa mesma esfera institucional.

Efectivamente, a praxis ambiental e territorial - no que isso pressupõe o envolvimento dos diversos actores sociais (e não só os agentes institucionais públicos) no progressivo estabelecimento de uma prática política, consensualmente debatida e contratualmente estabelecida, naquelas duas dimensões fundamentais - é, ainda, demasiado incipiente, porque demasiado parcelizada, mais movida por fenómenos nymby (not in my back yard), do que por uma perspectiva integrada, aos diversos níveis da sua incidência. Realmente, na instância propriamente política - cujos efeitos tendem a uma resolução de "soma zero" - quanto maior for a hegemonia institucional do sistema político, menor tenderá a ser o espaço da política, lugar onde, precisamente, a conflitualidade dos interesses se confronta e, eventualmente, se supera.

De certo modo, $o$ actual contexto económico e político parece favorecer alguma anomia sociológica, em que, nomeadamente no quadro da dinâmica societal, os movimentos sociais oscilam, ainda, entre uma certa "apatia social" e a própria "explosão do movimento". Sem dúvida que esse mesmo contexto está muito determinado pela famigerada globalização económica, mas também pela própria globalidade do ambiente. Procuremos, então, sintetizar esse mesmo contexto, a partir de alguns pares de questões-chave - que, reciprocamente, poderão ajudar a ilustrar aquele mesmo contexto - oriundas do "meio" em que tem estado envolvida a actual problemática ambiental.

Desde logo, o par da competitividade económica e da cooperação urbana e territorial: aquele 
contexto de globalização económica, abrindo-se, progressivamente, em múltiplas dimensões, sobretudo de ordem cultural e política, é contemporâneo, paradoxalmente, de uma acentuada fragmentação social. Em especial, ao nível das grandes aglomerações territoriais aquela fragmentação produz acentuadas situações de polarização social, extremando aqueles territórios numa profunda dualidade social entre os que podemos designar de "poderosos" (isto é, os que tem poder, seja económico, social ou cultural) e os realmente "excluídos" da sociedade - como é evidente, esta dualidade não é territorialmente homogénea, inclusive no interior de cada uma das regiões europeias e nacionais. Por outro lado, sabe-se como aquela globalização tem vindo a ser determinada por processos agressivos de competitividade económica e de especulação financeira - que, partindo da competitividade empresarial, rapidamente se assume, também, como competitividade territorial (urbana e/ou regional). Simplesmente, aquela mesma competitividade encontra limites no seu próprio interior, como ficou suficientemente ilustrado pelo Grupo de Lisboa (1994), o que coloca a questão da cooperação, eventualmente económica, mas mais inelutavelmente ao nível territorial. A título exemplar, as propostas centradas nas "redes de cidades", tal como vimos atrás, parecem constituir formas sustentáveis de cooperação urbana e territorial.

Depois, o par da solidariedade individual e da equidade social: não será controverso constatar que a sociedade contemporânea tem vindo a acentuar egoísmos individuais (e algum cinismo colectivo), na razão directa de uma progressiva parcelização da vida social. Em certa medida, aquela parcelização já estava inscrita no quadro da presente modernidade histórica, independentemente do debate sobre a sua eventual superação "pós-moderna". Nesse contexto, as políticas liberais e neoliberais permitiram reforçar aquela postura ideológica de uma progressiva individuação da vida social. Por isso, solidariedade individual e equidade social, sendo, igualmente, posturas de natureza ideológica, inscrevem-se, contudo, indelevelmente, na própria crítica dos processos de fragmentação social, que referimos atrás, mas também dos processos de individuação da vida social e cultural. A este nível, portanto, solidariedade e equidade constituem as duas faces de um mesmo projecto político que deve ter tradução, neste caso, ao nível da sustentabilidade territorial.

Finalmente, o par da sustentabilidade territorial e da subsidiariedade política: no quadro do dito desenvolvimento sustentável - que, para além de todas as ambiguidades, deve ser entendido como um desenvolvimento integrado, na medida em que procura integrar as diversas valências em jogo - o princípio da subsidiariedade apela, claramente, a modalidades descentralizadas de exercício do poder, no sentido em que (simplifico) tais modalidades tenderão a exercer-se, dominantemente, "de baixo para cima", em relação aos diversos níveis de exercício do poder político. Esta mesma postura de progressiva e assumida descentralização política, tenderá a apelar, igualmente, ao exercício cívico e político da "sociedade civil", mobilizando, deste modo, as associações de diversa natureza, as organizações de acção colectiva (como é o caso das organizações não governamentais) e os próprios movimentos sociais, nas suas formas mais ou menos organizadas. Em termos ambientais e territoriais, vemos como, uma vez mais, estamos perante duas faces de uma mesma postura social e política, o que não deixa de nos encaminhar, também aqui, para a referida sustentabilidade territorial.

Perante um tal quadro tão dilemático, que dizer - e que fazer - sobre a necessária sustentabilidade territorial do Sul, o que é o mesmo que questionar o território regional e nacional (para não irmos mais longe)? Talvez ir procurando a superação dos dilemas de partida. Ou seja, perante a dita competitividade, que se projecta, como sabemos, à escala global, avançar nas múltiplas formas de cooperação urbana e territorial; face à solidariedade individual, que em si mesma parece inócua, sublinhar a questão decisiva da equidade social; finalmente, o último dilema - que só o é num quadro de um desenvolvimento não sustentável - deve ser assumido de modo articulado e integrado, na medida em que sustentabilidade territorial e subsidiariedade política acabam por ser as duas faces de todo este mesmo debate - ou, como dissemos atrás, deverão constituir os dois momentos simultâneos de um assumido e contratualizado projecto político. 


\section{Referências Bibliográficas}

BRUNDTLAND, G. H. et al. (1987), Our Common Future, World Comission on Environment and Development, Oxford, Oxford University Press. (trad. port. O Nosso Futuro Comum, Lisboa, Meribérica-Liber, 1991).

FERREIRA, V. Matias (1998), "Património Urbano - A Memória da Cidade" in Urbanidade e Património, Lisboa, IGAPHE/Urbe, pp. 53-62.

FERREIRA, V. Matias (2002), Ambiente, Città e Sviluppo. Un Ambiente Urbano Sostenibile? in Fregolent, Laura e Indovina, Francesco (eds), Un Futuro Amico. Sostenibilità ed Equità, Milão, Franco Angeli. Posteriormente publicado in Cidades. Territórios e Comunidades, 4, Junho 2002, pp. 45-60.

FERREIRA, V. Matias (2004), Fascínio da Cidade. Memória e Projecto da Urbanidade, Lisboa, Ler Devagar.
FERREIRA, V. Matias (2007), Portugal. Território e Urbanidade in Ana Paula B. Horta (dir.) Sociologia Urbana, Lisboa, Universidade Aberta.

FERREIRA, V. Matias et al., (2008), Desenvolvimento Turístico Sustentável, Lisboa, Centro de Estudos Territoriais, Relatório final de investigação.

Grupo de Lisboa (1994), Limites à Competição, Lisboa, Publicações Dom Quixote.

MATTOSO, José (dir.) (1992), História de Portugal, 1. ${ }^{\circ}$ vol., Antes de Portugal, Lisboa, Círculo de Leitores.

OSBERNO e ARNULFO (Narrações pelos Cruzados) (1936), Conquista de Lisboa aos Mouros (1147), Lisboa, Câmara Municipal de Lisboa (Ed. bilingue, português e latim).

RIBEIRO, Orlando (1945), Portugal, o Mediterrâneo e o Atlântico, Coimbra, Coimbra Editora.

TORRES, Cláudio (1992), O Garb-Al-Andaluz in José Mattoso, op. cit., 361-437. 